\title{
1 Genetic Variation and Disease Severity of Respiratory Syncytial Viruses
}

2 Christopher S. Anderson ${ }^{1}$, Yun Zhang ${ }^{2}$, Anthony Corbett ${ }^{3}$, Chinyi Chu ${ }^{1}$, Alexander Grier ${ }^{5}$, Lu Wang ${ }^{3}$, Xing

3 Qiu $^{3}$, Mathew Mccall ${ }^{3}$, David J. Topham ${ }^{5}$, Edward E. Walsh ${ }^{6}$, Thomas J. Mariani ${ }^{1}$, Richard Scheuermann ${ }^{2}$

4 and Mary T. Caserta ${ }^{7}$

$5 \quad{ }^{1}$ Division of Neonatology, Department of Pediatrics, University of Rochester Medical Center, Rochester,

6 NY, USA.

$7 \quad$ 2J. Craig Venter Institute, La Jolla, CA, USA.

$8{ }^{3}$ Department of Biostatistics and Computational Biology, University of Rochester Medical Center,

9 Rochester, NY, USA.

$10{ }^{4}$ Department of Pediatrics, University of Rochester Medical Center, Rochester, NY, USA.

$11{ }^{5}$ Department of Microbiology and Immunology, University of Rochester Medical Center, Rochester, NY,

12 USA.

$13{ }^{6}$ Department of Medicine, University of Rochester Medical Center, Rochester, NY, USA.

$14{ }^{7}$ Division of Infectious Diseases, Department of Pediatrics, University of Rochester Medical Center,

15 Rochester, NY, USA.

16

17 Address for Correspondence:

18 Christopher S Anderson, $\mathrm{PhD}$

19 Department of Pediatrics

20 University of Rochester Medical Center

21601 Elmwood Ave, Box 850

22 Rochester, NY 14642, USA.

23 E-mail: christopher_anderson@urmc.rochester.edu

24

25 Mary T. Caserta, M.D.

26 Professor of Pediatrics 
bioRxiv preprint doi: https://doi.org/10.1101/2022 02.28.482432; this version posted March 2, 2022. The copyright holder for this preprint (which was not certified by peer review) is the author/funder, who has granted bioRxiv a license to display the preprint in perpetuity. It is made available under aCC-BY-NC-ND 4.0 International license.

27 Division of Infectious Diseases

28 University of Rochester Medical Center

29601 Elmwood Ave, Box 850

30 Rochester, NY 14642, USA.

31 E-mail: Mary Caserta@URMC.Rochester.edu

32

33 This original work was supported by the NIH/NIAID HHSN272201200005C, the University of Rochester

34 Pulmonary Training Fellowship NIH/NHLBI T32-HL066988, University of Rochester HSCCI Pilot Award

35 OP211341, the University of Rochester SAC Incubator Award.

36

37 Running title: RSV Variation and Disease

38 


\section{Abstract}

Respiratory Syncytial Virus (RSV) disease in newborns ranges from mild symptoms to severe disease requiring hospitalization. RSV is classified into two subtypes (RSVA and RSVB) based on antigenic and genetic differences. The role these genomic variations play in disease severity remains unknown. Genome sequences were obtained using next-generation RNA sequencing on archived frozen nasal swabs of young children ( $<8$ months-old) infected with RSV in Rochester, NY between 1977-1998. Samples were chosen

47 differences in the phylogeny and primary-protein structure during this time period. We found a significant association between RSV phylogeny over this time period and disease severity. For both subtypes, the Gprotein demonstrated the greatest amino acid substitutions, although the number of amino acid substitutions was higher in the RSVA subtype. We found a significant association between G-protein variation and

51 disease severity for RSVA, but not RSVB. For both subtypes, variation in the M2-2 protein was 52 significantly associated with disease severity. These results suggest that the genetic variability of RSV 53 proteins may contribute to disease severity in humans.

\section{Importance}

56 Each cold-season Respiratory Syncytial Virus (RSV) infects thousands of children in the US. Some will

57 display mild cold symptoms while others develop severe disease, sometimes resulting in lifelong lung

58 problems or fatality. RSV initiates infection and replicates in the nasopharynx. Substitutions in the RSV 59 genome can be found in clinically isolated nasal-swab samples of RSV infected children. Whether these 60 genome variations contribute to severe disease is unknown. Here we found a statistically significant 61 association between RSV phylogeny and disease severity. Furthermore, we found specific RSV proteins 62 (G and M2-2) whose amino acid variation was statistically associated with severe disease, although which 
bioRxiv preprint doi: https://doi.org/10.1101/2022.02.28.482432; this version posted March 2, 2022. The copyright holder for this preprint (which was not certified by peer review) is the author/funder, who has granted bioRxiv a license to display the preprint in perpetuity. It is made available under aCC-BY-NC-ND 4.0 International license.

63 protein was associated depended on subtype. Taken together, our results suggest that RSV genotype 64 contributed to disease severity over this time period.

65

66 Keywords: RSV, whole-genome, genetic variation, severe disease, respiratory infection 


\section{Introduction}

RSV is the leading cause of severe disease in young children. Viral infection occurs primarily in ciliated epithelial cells lining the human airways[1,2]. Acquisition of the virus occurs through either inhalation of aerosolized virus particles or direct contact of the airway epithelial cells with the virus, usually from on our hands [3]. Infection usually presents clinically as a mild respiratory disease with symptoms of rhinitis and cough being most common. For some individuals, especially young children during their first cold season, the virus presents as sometimes death[4,5]. Long-term effects of severe early-life RSV disease have also been reported[6,7].

The genomes of circulating RSV viruses are not the same and can be grouped into two subtypes (RSVA and RSVB) [3]. Within both subtypes significant genetic variation has occurred over time[8-12]. Moreover, a number of positively selected sites have been identified suggesting the variation is not random but an adaption to external pressure[8].

Most studies have focused on comparisons between RSV subtypes in relation to disease severity, with multiple studies demonstrating increased severity with RSVA, although these studies have been inconsistent[13]. Specific mutations such as those found in the F protein have been

84 shown to result in differences in RSV severity in mice[14]. Furthermore, recent studies of the newly 85 emerged RSV strains have demonstrated differences both in vitro and in vivo[15].

Many methods have been developed in order to statistically associate species variability and phenotype. Whole-viral-genome phylogenetics and phenotype (e.g. disease severity of host) can be statistically compared using a Bayesian association of phylogenetic topologies and phenotypes groups[16]. Additionally, non-parametric, distance-based methods that associate a trait with species diversity, including genetic diversity, have been developed using permutation 
composition among groups are similar[19-21]. Together, these methods provide means to associate RSV genetic variability with disease severity.

\section{Methods}

Sample Collection. Medical record data was used to identify nasal swab samples positive for RSV by PCR from children hospitalized for severe RSV disease and children seen in outpatient clinics presenting as mild disease. Clinical data, including age at time of infection, was also collected. Original sample collection occurred in the Rochester, NY area from 1977-1998. Nasal swabs were frozen and stored at $-80 \mathrm{C}$. Frozen samples were thawed and immediately lyzed with RNA lysis buffer. An RNA sequencing library was prepared and sequenced and 160 samples with wholegenome were obtained.

Phylogenetics Analysis and Trait Association. Full RSV genomes were aligned using MAFFT. Phylogenetic analysis and trees were produced using RaXML 1000. Bayesian Tip-association Significance testing (BaTS) was performed using the XXX software. The BaTS methods depend on tree topology and use bootstrap replicate trees. The BaTS algorithm applies three statistical methods to test the association between phylogeny and a trait (parsimony score, association index, and maximum exclusive single-state clade size).

Primary Protein Structure Analysis and Trait Association. Protein peptide sequences were translated in silico from each of the 11 protein-coding-regions for each RSV genome. Protein sequences were aligned using MUSCLE[22]. Pairwise Hamming distances between all aligned sequences were determine using the "stringdist" package in R version 3.4.4. Statistical relationships between the primary protein structures Hamming distance matrix and disease severity phenotype were determined using two statistical approaches. The first statistical method used to determine statistically significant differences between "outpatient" and "inpatient" derived RSV strains was a multivariate test of location in the Hamming distance matrix using the adonis 2 function from the Vegan package in R version 3.4.4. 9999 permutations were performed to determine empirical null. 
The second approach used a similar method, anosim function from the Vegan package in $\mathrm{R}$ version 3.4.4., but has been reported to be less effected by limited degrees of freedom. 9999 permutations were performed to determine empirical null.

121 Association with Disease Severity and Amino Acid Substitutions at each Residue. We used the meta-

122 CATS pipeline [23] to identify statistically significant amino acid positions of RSVA or RSVB subtypes 123 with disease severity status (mild/severe). At each position a chi-square test of independence and Pearson's 124 chi-square test is performed to calculate a $p$-value.

\section{Results}

127 RSV viruses were sequenced from nasal swab samples obtained from young children infected in 128 Rochester, New York between 1977 and 1998. Samples were chosen to represent roughly equal sex (42\% Female and 58\% male). Samples were obtained from children in order to equally represent both mild (outpatient; 87/160 (54\%)) and severe (inpatient; 73/160 46\%) disease.

131 Samples were chosen to enrich for primary infection sequences by choosing samples of subject that 132 were infected between 0 and 0.8 months old (single "cold season"). PCR-based RSV subtyping 133 data was used in attempt to equally represent A and B subtypes (RSVA $=58 \%$ and RSVB $=42 \%$ ).

134 The number of samples varied year to year (2 - 14 samples per year) with an average of 7.27 135 samples per year over the 21-year time frame.

Phylogenetic analysis of RSV strains from 1977 until 1998 separated into two distinct linages corresponding to the RSV A and B subtypes (Figure 1). Using a Bayesian approach to phylogenetic association (BEAST), we found a very high consensus on topology. The BaTS algorithm was used to determine if any association between phylogenetics was associated with disease severity status. Phylogeny-trait association demonstrated significant differences between trait (mild/severe 
144

145

146

147

148

149

150

151

152

153

154

155

156

157

158

159

160

161

162

163

164

165

166

167

168

exclusive single-state clade size, which is expected to be larger when tips all share the same trait, were significant for the severe trait, but not mild.

Of the $11 \mathrm{RSV}$ proteins, the G protein, for both subtypes, showed the maximum number of total amino acid substitutions $($ RSVA G protein $=64$, RSVB G protein $=53$; Figure $2 \mathrm{~A}$ ) as well as the greatest percent change per amino acid length of any protein (RSVA G protein $=21 \%$, RSVB G protein $=17 \%$; Figure $2 \mathrm{~B}$ ). The M2-2 protein was also one of the most variable proteins both in the number of total amino acids (RSVA M2-2 protein $=16$, RSVB M2-2 protein $=11)$ and percent change per protein length $($ RSVA M2-2 protein $=18 \%$, RSVB M2-2 protein $=12 \%)$. The L protein showed many substitutions for both subtypes $($ RSVA L protein $=43$, RSVB L protein $=30$ ) although the per amino acid change was moderate (RSVA L protein $=2 \%$, RSVB L protein $=1 \%)$. Alternatively, the SH protein and F protein showed lower numbers of amino acid substitutions $($ RSVA SH protein $=5$, RSVB SH protein $=6$; RSVA F protein $=14$, RSVB F protein $=10)$, but SH showed a moderate change per amino acid compared to other proteins (RSVA SH protein $=$ $8 \%$, RSVB SH protein $=9 \%$ ) and the F protein showed a minimal number of substitutions per protein length $($ RSVA F protein $=2 \%$, RSVB F protein $=2 \%)$. All other proteins showed both minimal substitutions $(3-6)$ and percent changes $(1-4 \%)$.

We next determined if amino acid variation in specific viral proteins were associated with disease severity. Using two permutation-based statistical approaches, we determined if amino acid variability was associated with disease phenotype (mild/severe). We found that in both subtypes the M2-2 protein was significantly associated with disease severity (Table 2; Figure 3). For the RSV A subtype, the G protein was also significantly associated with disease severity. The NS2 protein was also significantly associated with disease severity in the RSVB subtype, although only for one statistical test. 
170 We sought to evaluate if any specific mutations were significantly associated with disease severity.

171 We compared each residue in the RSVA G and M2-2 proteins and RSVB M2-2 proteins with

172 disease severity. Two out of the three proteins, RSVA G and RSVB M2-2, had significant

173 mutations associated with disease severity (Table 3). RSV A G-protein had seven amino acids

174 associated severity status, while the RSVB M2-2 protein had three amino acids associated. Taken

175 together, our results suggest that certain genetic variations in RSV may be more likely to be seen

176 in viruses isolated from young children hospitalized with RSV.

\section{Discussion}

179 We sought to provide insight into RSV-associated severe respiratory disease in young children experiencing their primary infection. Although many host factors are recognized as contributors to severe disease[5], the contribution of the virus genetics has not been well explored. In the study, we assessed genomic variation of RSV viruses that circulated in Rochester, New York from 1977 - 1998. Our findings confirm that the RSV genotype changes over time and multiple genotypes

184 circle each year. Furthermore, our results demonstrate that RSV genetic variation is not spatially

185 restricted and local regions are exposed to a multitude of unique RSV strains. We compared RSV

186 sequence variation and disease severity using both phylogenetic and non-phylogenetic approaches.

187 Phylogenetic approaches demonstrated that both tree topography, including monophyletic clades, were associated with severe disease. Lastly, our results suggest that RSV strains with specific amino acid substitutions in the G or M2-2 proteins contribute to disease severity in young children.

191 What specific impact amino acid substitutions in the surface proteins of RSV have on the host defense and if these changes result in antigenic drift is still largely unexplored, although the recently emerged ON1 RSVA strain containing a duplication in G has been shown to cause increase severe disease[24]. We found changes in the G protein were the most predominant. Additionally, the SH 
varied, but was not associated with disease severity during primary infection, although others have demonstrate changes in $\mathrm{F}$ that do increase disease severity[14]. Future studies will be needed to better understand the relationship between surface protein mutation and RSV disease.

We were surprised to see the structural protein M2-2 was associated with severity. M2-2 has been shown to be involved in viral RNA transcription and replication regulations. Furthermore, a current vaccine candidate has a M2-2 gene deletion that attenuates the virus, potentially providing protection, but resulting in mild disease. Whether variation in the M2-2 gene effects the transcription/replication regulation process is unknown.

Taken together, our results suggest that RSV variation can impact disease severity. Although our studies were not designed to investigate mechanism or causality, they do suggest that changes in RSV genes are associated with disease severity in the very young experiencing a primary infection. Whether these changes are due to the adaptive immune response, or random genetic drift, is still unknown and future studies will be needed to confirm if variation the RSV genome affects disease severity.

\section{Acknowledgements}

214 We would like to thank all sample donors for their contribution to the study. The original work was 215 supported by the University of Rochester Pulmonary Training Grant T32-HL066988, and the Health 216 Sciences Center for Computational Innovation Pilot Award OP211341.

\section{References} respiratory syncytial virus receptor in pediatric human lung, Pediatr. Res. 87 (2020) 862-867. doi:10.1038/s41390-019-0677-0.

[2] K.-I. Jeong, P.A. Piepenhagen, M. Kishko, J.M. DiNapoli, R.P. Groppo, L. Zhang, et al., CX3CR1 Is Expressed in Differentiated Human Ciliated Airway Cells and Co-Localizes with 
Respiratory Syncytial Virus on Cilia in a G Protein-Dependent Manner, PLoS ONE. 10 (2015) e0130517. doi:10.1371/journal.pone.0130517.

[3] B.N. Fields, Fields Virology, Stanford University Press, 2013. doi:10.11126/stanford/9780804770750.001.0001.

[4] T. Shi, D.A. McAllister, K.L. O'Brien, E.A.F. Simoes, S.A. Madhi, B.D. Gessner, et al., Global, regional, and national disease burden estimates of acute lower respiratory infections due to respiratory syncytial virus in young children in 2015: a systematic review and modelling study, Lancet. 390 (2017) 946-958. doi:10.1016/S0140-6736(17)30938-8.

[5] M.T. Caserta, X. Qiu, B. Tesini, L. Wang, A. Murphy, A. Corbett, et al., Development of a Global Respiratory Severity Score for Respiratory Syncytial Virus Infection in Infants, J. Infect. Dis. 215 (2017) 750-756. doi:10.1093/infdis/jiw624.

[6] N. Sigurs, P.M. Gustafsson, R. Bjarnason, F. Lundberg, S. Schmidt, F. Sigurbergsson, et al., Severe respiratory syncytial virus bronchiolitis in infancy and asthma and allergy at age 13, Am. J. Respir. Crit. Care Med. 171 (2005) 137-141. doi:10.1164/rccm.200406-730OC.

[7] P. Wu, T.V. Hartert, Evidence for a causal relationship between respiratory syncytial virus infection and asthma, Expert Rev Anti Infect Ther. 9 (2011) 731-745. doi:10.1586/eri.11.92.

[8] A. Trento, M. Viegas, M. Galiano, C. Videla, G. Carballal, A.S. Mistchenko, et al., Natural history of human respiratory syncytial virus inferred from phylogenetic analysis of the attachment (G) glycoprotein with a 60-nucleotide duplication, J. Virol. 80 (2006) 975-984. doi:10.1128/JVI.80.2.975-984.2006.

[9] H. Chi, K.-L. Hsiao, L.-C. Weng, C.-P. Liu, H.-F. Liu, Persistence and continuous evolution of the human respiratory syncytial virus in northern Taiwan for two decades, Sci. Rep. 9 (2019) 4704-9. doi:10.1038/s41598-019-41332-9.

[10] J.A. Melero, M.L. Moore, Influence of respiratory syncytial virus strain differences on pathogenesis and immunity, Curr. Top. Microbiol. Immunol. 372 (2013) 59-82. doi:10.1007/978-3-642-38919-1_3.

[11] W.M. Sullender, Respiratory syncytial virus genetic and antigenic diversity, Clin. Microbiol. Rev. 13 (2000) 1-15- table of contents. doi:10.1128/cmr.13.1.1-15.2000.

[12] L. Tan, F.E.J. Coenjaerts, L. Houspie, M.C. Viveen, G.M. van Bleek, E.J.H.J. Wiertz, et al., The comparative genomics of human respiratory syncytial virus subgroups A and B: genetic variability and molecular evolutionary dynamics, J. Virol. 87 (2013) 8213-8226. doi:10.1128/JVI.03278-12.

[13] S. Vandini, C. Biagi, M. Lanari, Respiratory Syncytial Virus: The Influence of Serotype and Genotype Variability on Clinical Course of Infection, Int J Mol Sci. 18 (2017). doi:10.3390/ijms18081717.

[14] M.L. Moore, M.H. Chi, C. Luongo, N.W. Lukacs, V.V. Polosukhin, M.M. Huckabee, et al., A chimeric A2 strain of respiratory syncytial virus (RSV) with the fusion protein of RSV strain line 19 exhibits enhanced viral load, mucus, and airway dysfunction, J. Virol. 83 (2009) 41854194. doi:10.1128/JVI.01853-08.

[15] F. Midulla, G. Di Mattia, R. Nenna, C. Scagnolari, A. Viscido, G. Oliveto, et al., Novel Variants of Respiratory Syncytial Virus A ON1 Associated With Increased Clinical Severity of Bronchiolitis, J. Infect. Dis. 222 (2020) 102-110. doi:10.1093/infdis/jiaa059.

[16] J. Parker, A. Rambaut, O.G. Pybus, Correlating viral phenotypes with phylogeny: accounting for phylogenetic uncertainty, Infect. Genet. Evol. 8 (2008) 239-246.

doi:10.1016/j.meegid.2007.08.001.

[17] M.J. Anderson, A new method for non-parametric multivariate analysis of variance, Austral Ecology. 26 (2001) 32-46. doi:10.1111/j.1442-9993.2001.01070.pp.x.

[18] J.E. Bennett, R. Dolin, M.J. Blaser, Mandell, Douglas, and Bennetts. Principles and Practice of Infectious Diseases, Philadelphia: Churchill Livingstone, 2015.

[19] B.H. McArdle, M.J. Anderson, FITTING MULTIVARIATE MODELS TO COMMUNITY DATA: A COMMENT ON DISTANCE-BASED REDUNDANCY ANALYSIS, Ecology. 82 
(2001) 290-297. doi:10.1890/00129658(2001)082[0290:FMMTCD]2.0.CO;2@10.1002/(ISSN)19399170(CAT)VirtualIssues(VI)scECY.

[20] M.J. Anderson, Distance-based tests for homogeneity of multivariate dispersions, Biometrics. 62 (2006) 245-253. doi:10.1111/j.1541-0420.2005.00440.x.

[21] M.J. Anderson, K.E. Ellingsen, B.H. McArdle, Multivariate dispersion as a measure of beta diversity, Ecol. Lett. 9 (2006) 683-693. doi:10.1111/j.1461-0248.2006.00926.x.

[22] R.C. Edgar, MUSCLE: multiple sequence alignment with high accuracy and high throughput, Nucleic Acids Res. 32 (2004) 1792-1797. doi:10.1093/nar/gkh340.

[23] B.E. Pickett, M. Liu, E.L. Sadat, R.B. Squires, J.M. Noronha, S. He, et al., Metadata-driven comparative analysis tool for sequences (meta-CATS): an automated process for identifying significant sequence variations that correlate with virus attributes, Virology. 447 (2013) 45-51. doi:10.1016/j.virol.2013.08.021.

[24] A. Streng, D. Goettler, M. Haerlein, L. Lehmann, K. Ulrich, C. Prifert, et al., Spread and clinical severity of respiratory syncytial virus A genotype ON1 in Germany, 2011-2017, BMC Infect. Dis. 19 (2019) 613-10. doi:10.1186/s12879-019-4266-y.

Figure 1. Genomic Variation of the RSV Genome. Aligned whole-genome RSV sequences of viruses collected from nasal swabs of children $>8$ months-old infected in their first "cold season" between 19771998 in Rochester, NY. Phylogenetic trees were fitted using a Bayesian approach (BEAST). To visualize both uncertainty in node heights and uncertainty in topology phylogenetic trees were visualized using DensiTree.

Figure 2. Comparison of Amino Acid Variation in Across RSV Proteins. RSV protein sequences within subtypes were aligned using MUSCLE. The number of amino acid substitution between each RSV sequence was calculated. (A) Boxplot of the number of amino acid substitutions between all RSV proteins by subtype. (B) Boxplot of the percentage of number of amino acid substitutions divided by the amino acid length of the protein between all RSV proteins by subtype.

Figure 3. Primary Protein Structure Variability Among RSV G and M2-2 Proteins. Protein sequences for G and M2-2 proteins from RSVA and RSVB subtypes were aligned separately. The number of amino acid substitutions were calculated between all strains resulting. Principal coordinate analysis was performed to demonstrate amino acid variability in reduced dimensional space. Ellipses are centered on centroids with 1 standard deviation. Points are colored by disease severity status; red = mild/outpatient, black = severe/inpatient. When points contain multiple sequences and from patients of both disease types, points are colored by the more numerous disease type. 
Figure 1

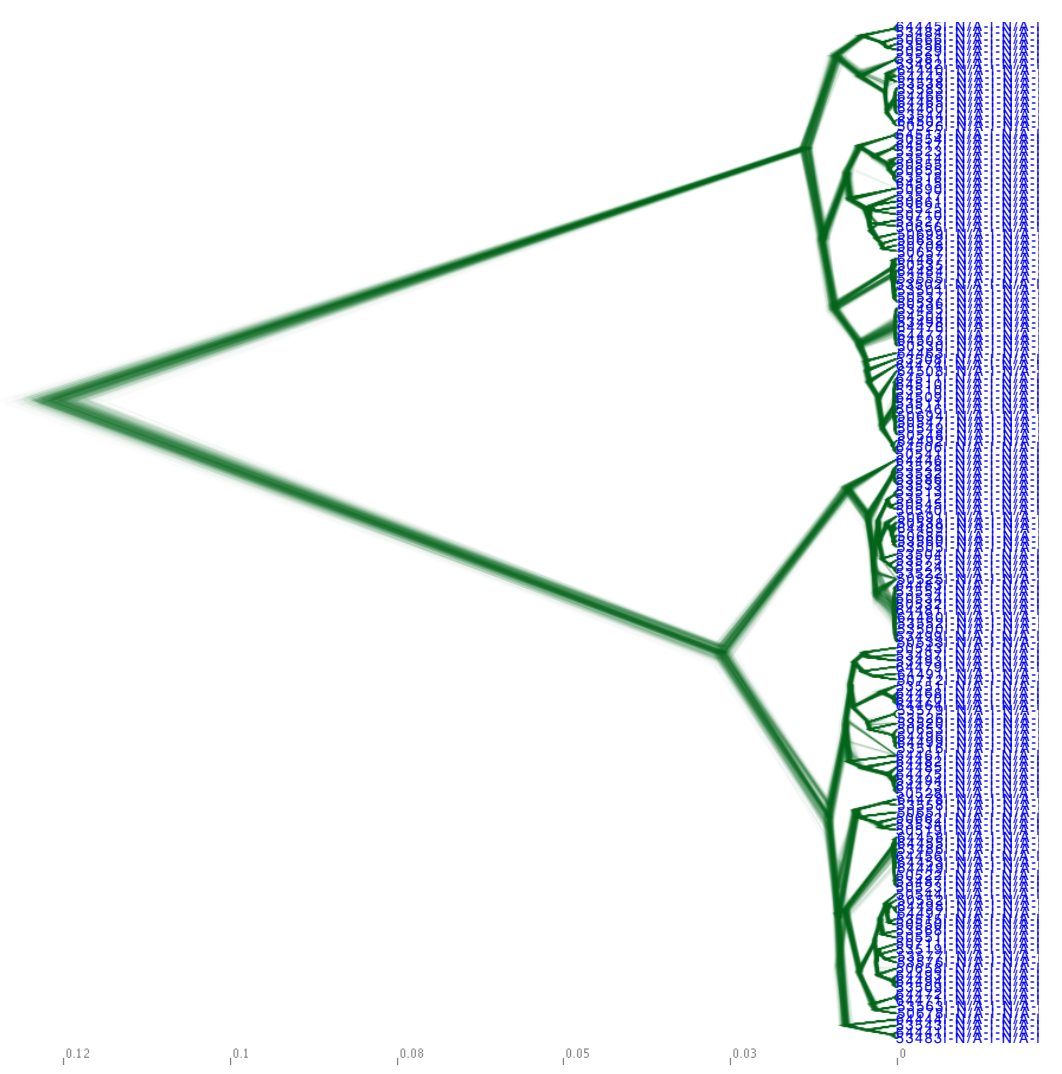




\section{Table 1}

\begin{tabular}{|l|r|r|l|l|r|r|r|}
\hline Statistic & $\begin{array}{l}\text { lobserved } \\
\text { mean }\end{array}$ & $\begin{array}{l}\text { lower } \\
95 \% \mathrm{Cl}\end{array}$ & $\begin{array}{l}\text { lupper } \\
95 \% \mathrm{CU}\end{array}$ & $\begin{array}{l}\text { null } \\
\text { mean }\end{array}$ & $\begin{array}{l}\text { lower } \\
95 \% \mathrm{Cl}\end{array}$ & $\begin{array}{l}\text { lupper } \\
95 \% \mathrm{Cl} \text { e }\end{array}$ & significanc \\
\hline Al & 7.025 & 6.305 & 7.752 & 8.862 & 7.387 & 1 & 0.023 \\
\hline & & & & & & 58.77 & \\
PS & 45.935 & 44.000 & 47.000 & 53.798 & 48.308 & 8 & 0.012 \\
\hline MC (Severe) & 9.000 & 9.000 & 9.000 & 4.809 & 3.153 & 7.233 & 0.027 \\
\hline MC (Mild) & 4.022 & 4.000 & 4.000 & 3.896 & 2.632 & 6.000 & 0.503 \\
\hline
\end{tabular}


A
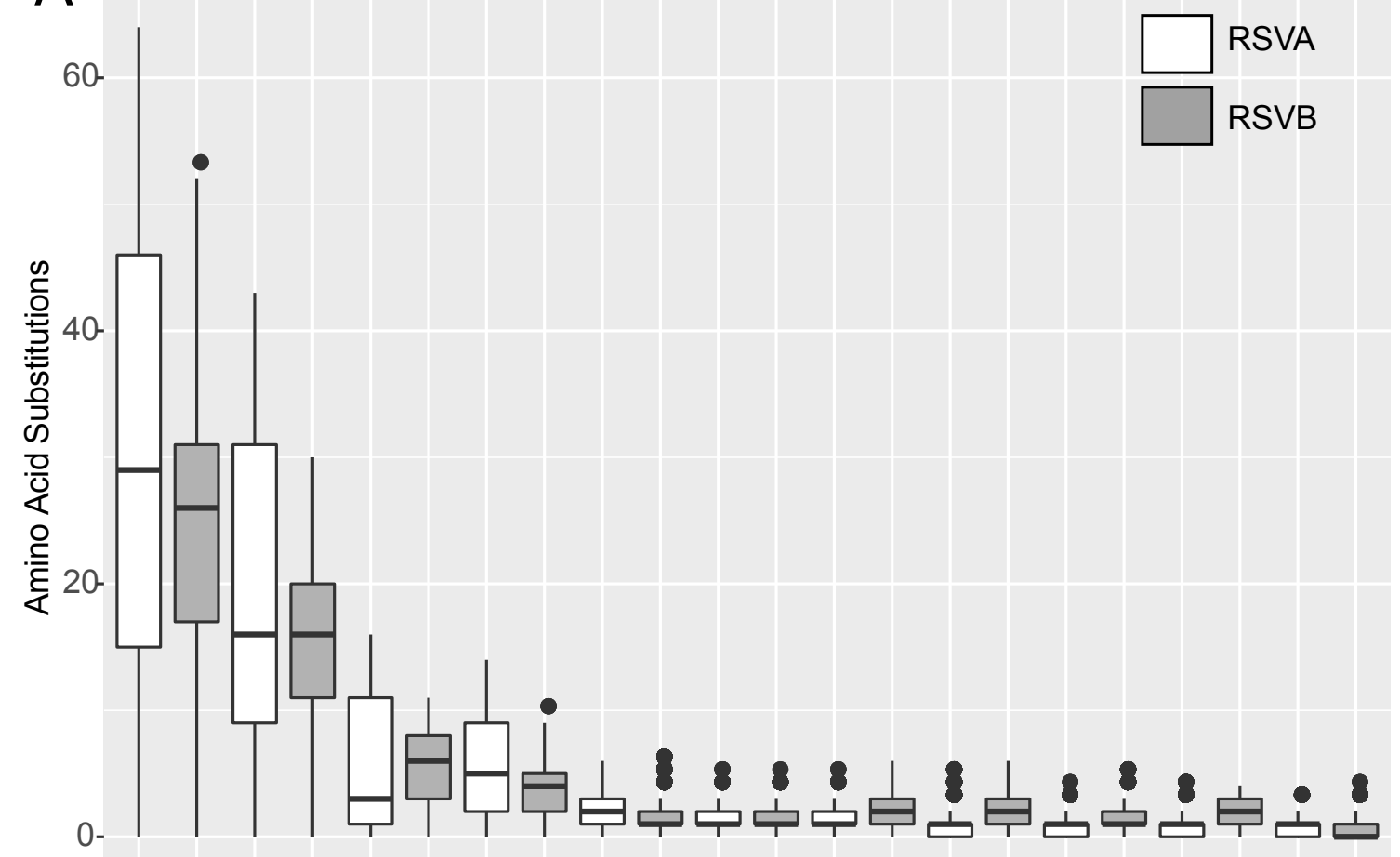

B

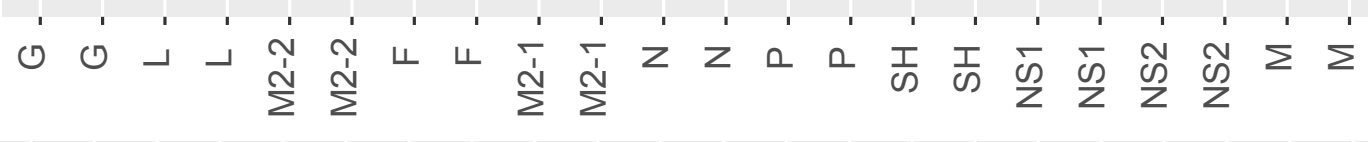

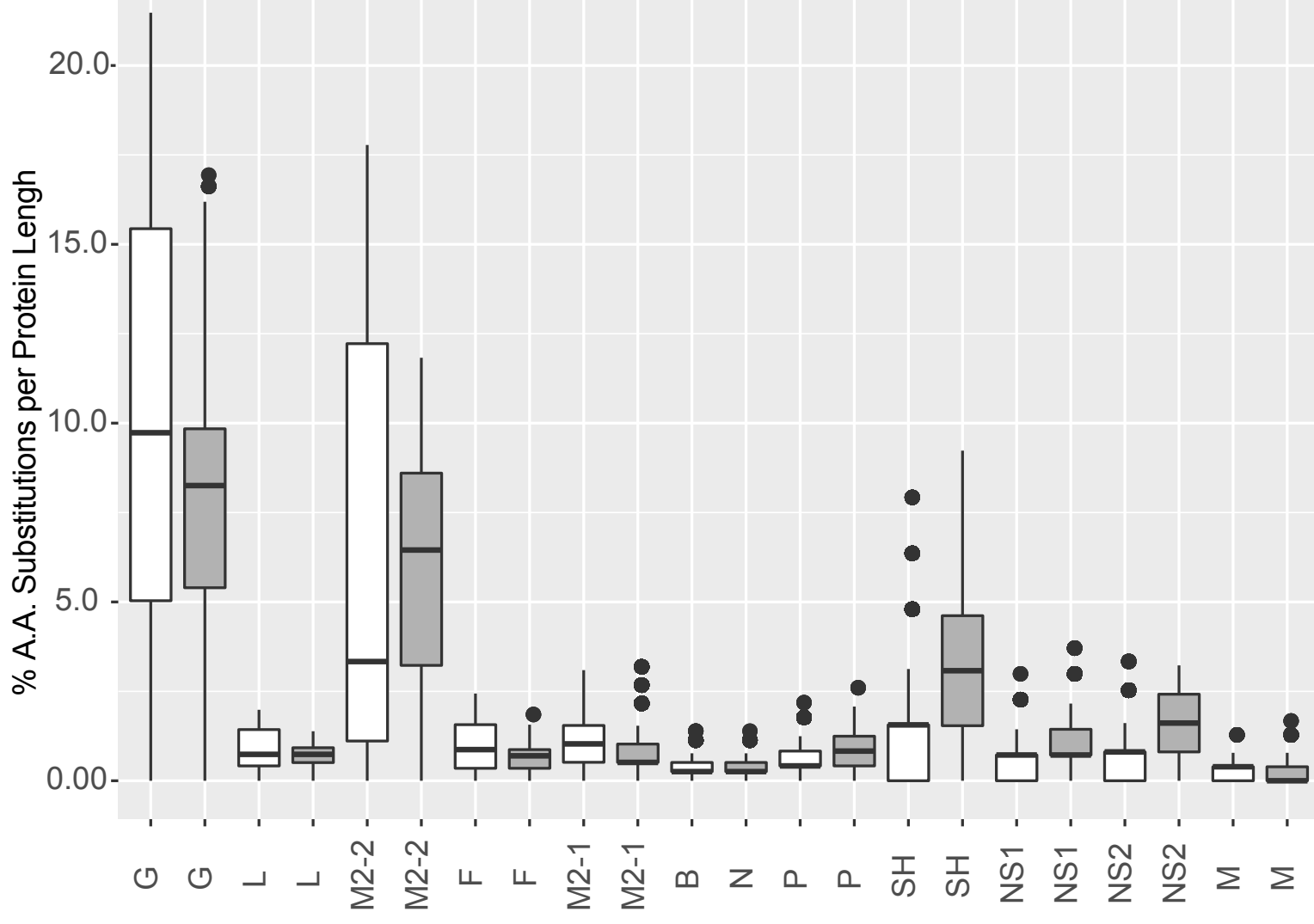

Figure 2 
Table 2

\begin{tabular}{|c|c|c|c|c|c|c|c|}
\hline Protein & Subtype & $\begin{array}{c}\text { Anosim } \\
\text { Rval }\end{array}$ & $\begin{array}{c}\text { Anosim } \\
\text { pval }\end{array}$ & $\begin{array}{c}\text { Anosim } \\
\text { pval.adj }\end{array}$ & $\begin{array}{c}\text { Adonis2 } \\
\text { Fval }\end{array}$ & $\begin{array}{c}\text { Adonis2 } \\
\text { pval }\end{array}$ & $\begin{array}{c}\text { Adonis2 } \\
\text { pval.adj }\end{array}$ \\
\hline G & A & 0.122 & 0.001 & $0.011^{*}$ & 9.438 & 0.001 & $0.011^{*}$ \\
\hline G & B & -0.140 & 0.999 & 0.999 & -4.832 & 1.000 & 1.000 \\
\hline L & A & 0.026 & 0.068 & 0.166 & 2.916 & 0.071 & 0.137 \\
\hline L & B & -0.005 & 0.515 & 0.629 & 2.083 & 0.081 & 0.137 \\
\hline M2-2 & A & 0.119 & 0.001 & $0.011^{*}$ & 7.251 & 0.004 & $0.022^{*}$ \\
\hline M2-2 & B & 0.105 & 0.007 & $0.051^{*}$ & 5.078 & 0.002 & $0.015^{*}$ \\
\hline F & A & 0.038 & 0.040 & 0.126 & 2.602 & 0.093 & 0.138 \\
\hline F & B & 0.085 & 0.068 & 0.166 & 3.573 & 0.023 & 0.072 \\
\hline M2-1 & A & 0.014 & 0.153 & 0.259 & 2.843 & 0.073 & 0.137 \\
\hline M2-1 & B & 0.040 & 0.209 & 0.307 & 3.178 & 0.036 & 0.088 \\
\hline N & A & 0.004 & 0.306 & 0.396 & 2.398 & 0.100 & 0.138 \\
\hline N & B & 0.101 & 0.024 & 0.114 & 2.179 & 0.095 & 0.138 \\
\hline P & A & 0.011 & 0.197 & 0.307 & 1.129 & 0.337 & 0.412 \\
\hline P & B & 0.109 & 0.026 & 0.114 & 6.393 & 0.017 & 0.072 \\
\hline SH & A & 0.020 & 0.111 & 0.218 & 2.676 & 0.075 & 0.137 \\
\hline SH & B & -0.079 & 0.975 & 0.999 & 0.327 & 0.765 & 0.842 \\
\hline NS1 & A & 0.041 & 0.036 & 0.126 & 4.224 & 0.026 & 0.072 \\
\hline NS1 & B & -0.066 & 0.940 & 0.999 & 0.097 & 0.885 & 0.927 \\
\hline NS2 & A & 0.020 & 0.119 & 0.218 & 1.148 & 0.321 & 0.412 \\
\hline NS2 & B & -0.027 & 0.695 & 0.805 & 7.075 & 0.001 & $0.011^{*}$ \\
\hline M & A & 0.021 & 0.091 & 0.200 & 5.191 & 0.021 & 0.072 \\
\hline M & B & 0.022 & 0.303 & 0.396 & 0.244 & 0.721 & 0.835 \\
\hline
\end{tabular}

${ }^{*} p$ value $\leq 0.05$ 
Table 3

\begin{tabular}{|c|c|c|c|c|c|c|c|}
\hline Subtype & Protein & Position & $\begin{array}{c}\text { Chi- } \\
\text { square } \\
\text { Value }\end{array}$ & P-value & $\begin{array}{l}\text { Degree } \\
\text { Freedom }\end{array}$ & $\begin{array}{c}\text { Severe Residue } \\
\text { Diversity }\end{array}$ & $\begin{array}{c}\text { Mild Residue } \\
\text { Diversity }\end{array}$ \\
\hline A & $\mathbf{G}$ & 1528 & 8.913 & 0.0116 & 2 & $7 \mathrm{~L}, 15 \mathrm{P}, 20 \mathrm{~S}$ & $5 \mathrm{~L}, 34 \mathrm{P}, 12 \mathrm{~S}$ \\
\hline A & G & 1327 & 7.558 & 0.02285 & 2 & $14 L, 4 P, 24 Q$ & $11 \mathrm{~L}, 40 \mathrm{Q}$ \\
\hline A & $\mathbf{G}$ & 1298 & 4.159 & 0.04142 & 1 & $22 \mathrm{~N}, 20 \mathrm{~S}$ & $15 \mathrm{~N}, 36 \mathrm{~S}$ \\
\hline A & G & 1496 & 8.215 & 0.04176 & 3 & $22 \mathrm{H}, 18 \mathrm{~L}, 2 \mathrm{~N}$ & $37 \mathrm{H}, 12 \mathrm{~L}, 2 \mathrm{Y}$ \\
\hline A & G & 1524 & 4.007 & 0.0453 & 1 & $22 L, 20 P$ & $38 L, 13 P$ \\
\hline A & G & 1324 & 6.123 & 0.04682 & 2 & $18 \mathrm{I}, 4 \mathrm{~N}, 20 \mathrm{~T}$ & $12 \mathrm{I}, 2 \mathrm{~N}, 37 \mathrm{~T}$ \\
\hline A & $\mathbf{G}$ & 1414 & 3.923 & 0.04764 & 1 & $24 \mathrm{~K}, 18 \mathrm{R}$ & $40 \mathrm{~K}, 11 \mathrm{R}$ \\
\hline B & M2-2 & 2341 & 5.57 & 0.01827 & 1 & $30 \mathrm{I}, 14 \mathrm{~V}$ & $8 \mathrm{I}, 15 \mathrm{~V}$ \\
\hline B & M2-2 & 2354 & 4.905 & 0.02678 & 1 & $41 \mathrm{H}, 3 \mathrm{Y}$ & $16 \mathrm{H}, 7 \mathrm{Y}$ \\
\hline B & M2-2 & 2551 & 4.905 & 0.02678 & 1 & $3 \mathrm{D}, 41 \mathrm{E}$ & $7 \mathrm{D}, 16 \mathrm{E}$ \\
\hline
\end{tabular}

